\title{
ANALISIS JENIS LAYANAN PENDIDIKAN DAN NON PENDIDIKAN YANG PENTING BAGI PENINGKATAN KEPUASAN MAHASISWA (STUDI KASUS: FAKULTAS TEKNIK UNIVERSITAS DIPONEGORO)
}

\author{
Aries Susanty ${ }^{*}$, Haryo Santoso, Pramudiastuti A. Nursyachbani, \\ Program Studi Teknik Industri, Fakultas Teknik, Universitas Diponegoro, \\ Jl. Prof. Soedarto, SH, Kampus Undip Tembalang, Semarang, Indonesia 50275
}

(Received: August 07, 2017/ Accepted: January 25, 2018)

\begin{abstract}
Abstrak
Penelitian ini memiliki dua tujuan. Pertama, penelitian ini bertujuan untuk mengindentifikasi item layanan pendidikan dan non pendidikan yang dianggap penting untuk peningkatan kepuasan mahasiswa Fakultas Teknik Univesitas Diponegoro (UNDIP). Kedua, penelitian ini bertujuan untuk menyusun sejumlah rekomendasi untuk perbaikan atas item layanan pendidikan dan non pendidikan yang dianggap penting tersebut. Terdapat 7 dimensi dan 28 item layanan yang digunakan untuk mengindentifikasi jenis layanan pendidikan dan non Pendidikan yang diterima oleh mahasiswa Fakultas Teknik UNDIP. Penelitian ini menggunakan Metode Kano dan Taguchi untuk mengindentifikasi item layanan pendidikan dan non pendidikan yang dianggap paling penting. Dalam hal ini, Metode Kano digunakan untuk memilih sejumlah item layanan pendidikan dan non pendidikan yang termasuk dalam kelompok attractive dan one-dimentional. Adapun Metode Taguchi digunakan untuk dua hal, yang pertama yaitu memverifikasi hasil pengelompokan dari Metode Kano sehingga diperoleh hasil yang lebih optimal dan mengurutkan prioritas perbaikan dari item-item layanan yang termasuk dalam kelompok attractive dan one-dimentional. Data untuk penelitian ini diperoleh dari hasil pengisian kuesioner oleh 120 responden untuk kuesioner Kano dan 60 responden untuk kuesioner Taguchi. Hasil pengolahan data dengan menggunakan Metode Kano menunjukkan bahwa terdapat 6 item layanan yang termasuk dalam kategori one-dimensional dan terdapat 2 item layanan .yang termasuk dalam kategori attractive. Selanjutnya, pengolahan data dengan menggunakan Metode Taguchi diperoleh bahwa terdapat 2 item layanan yang perpindah dari one-dimensional ke attractive dan 1 item layanan yangberpindah dari attractive ke one-dimensional.
\end{abstract}

Kata Kunci: Layanan Pendidikan dan Non Pendidikan; Peningkatan Kepuasan Mahasiswa; Faktultas Teknik UNDIP; Metode Kano; Metode Taguchi

\begin{abstract}
[Analysis of the type of educational and non-educational services that are important for the enhancement of student satisfaction (case study Faculty of Engineering, Diponegoro University)] This research has two objective. First this study aims to identify the type of educational and noneducational services that are important for the satisfaction's enhancement of the student of Faculty Engineering, Diponegoro University. Second, this study aims to formulate some recommendation for improving the type of educational and non-educational services that are important for the satisfaction's enhancement of the student of Faculty Engineering. There are 7 dimensions and 28 indicators used to identify the type of educational and non-educational received by the student. This research uses the Kano and Taguchi method to identify the type of educational and non-educational services that are important for student. In this case, the Kano method is used to identify educational and non-educational services that are include attractive and one-dimensional categories. Whereas the Taguchi method is used to verify Kano's categorize result for getting more optimal result than Kano method and to put priorities in the right order of those services that are include attractive and one-dimensional categories. Data for this research is got from questionnaires that were distributed to 120 respondents for Kano method and 60 respondents for Taguchi method. Kano method's result showed that there are 6 type of services that are include in one-dimensional category and 2 type of services that are

${ }^{*}$ Penulis Korespondensi.

e-mail: ariessusnty@gmail.com include in attractive category. However, based on validation result that is using Taguchi method showed that there are 5 type
\end{abstract}


of services that are include in one-dimensional category and 3 type of services that are include in attractive category.

Keywords: Educational and Non-educational Services; Satisfaction's Enhancement of Student; Faculty of Engineering Diponegoro Univesity; Kano Method; Taguchi Method.

\section{PENDAHULUAN}

Pendidikan merupakan kebutuhan primer bagi masyarakat. Salah satu lembaga pendidikan yang menjadi harapan bagi masyarakat untuk dapat menghasilkan sumber daya manusia yang lebih bermutu adalah perguruan tinggi. Keadaan persaingan global yang semakin kompetitif menuntut lembaga pendidikan, khususnya perguruan tinggi, untuk memperhatikan mutu pendidikan sehingga dapat menghasilkan sumber daya manusia yang mampu bersaing secara global (Alves \& Raposo, 2007). Perguruan Tinggi Negeri (PTN) merupakan salah satu lembaga pendidikan yang banyak dipilih masyarakat untuk melanjutkan pendidikan ke jenjang yang lebih tinggi, disamping Perguruan Tinggi Swasta (PTS). Sampai dengan saat ini, jumlah PTN di Indonesia baru berjumlah 134 perguruan tinggi, sedangkan jumlah PTS mencapai 4.200 perguruan tinggi. Berdasarkan hal tersebut, pada awal tahun 2016, Menteri Riset Teknologi dan Pendidikan Tinggi, menetapkan status negeri yang baru kepada 36 perguruan tinggi. Status tersebut diberikan kepada 7 perguruan tinggi baru dan 29 perguruan tinggi swasta yang dinegerikan (Sukamto, 2016).

Universitas Diponegoro merupakan salah satu dari 134 PTN di Indonesia. Berdasarkan klasifikasi dan pemeringkatan perguruan tinggi di Indonesia yang dilakukan oleh Kementrian Riset Teknologi dan Pendidikan Tinggi pada tahun 2016, Universitas Diponegoro (UNDIP) menempati peringkat 9. Salah satu cara agar UNDIP tetap merupakan perguruan tinggi yang terbaik, UNDIP senantiasa berupaya untuk menjaga kualitas atas layanan yang diberikan, Dalam hal ini, UNDIP (khususnya Fakultas Teknik), telah memiliki sistem evaluasi atas kualitas layanan yang diberikan yang dikenal dengan Evaluasi Proses Belajar Mengajar (Evaluasi PBM). Evaluasi ini dilakukan oleh mahasiswa pada setiap akhir semester. Namun demikian sistem Evaluasi PBM memiliki beberapa kekurangan dan salah satu diantaranya, hasil Evalusi PBM tidak memfasilitasi Fakultas Teknik UNDIP untuk mengidentifikasi item layanan mana yang penting bagi mahasiswa, yang dapat meningkatkan kepuasan mahasiswa secara significan. Evaluasi PBM hanya mengindenttifikasi item-item layanan yang sudah baik dan faktor-faktor layanan yang masih kurang. Padahal, dalam item-item layanan yang sudah baik maupun yang masih kurang tersebut, mungkin terdapat item-item layanan yang secara sigfnifikan dapat meningkatkan kepuasan mahasiswa. Dengan demikian, berdasarkan kekurangan yang dimiliki oleh Evaluasi PBM, penelitian ini bermaksud untuk melakukan proses evaluasi atas layanan yang diberikan oleh Fakultas Teknik, dimana proses evaluasi tersebut mampu mengidenfikasi item layanan pendidikan dan non-pendidikan yang dianggap signifikan untuk peningkatan kepuasan mahasiswa Fakultas Teknik UNDIP. Disamping itu, penelitian ini juga akan memberikan rekomendasi perbaikan yang dapat dilakukan untuk meningkatkan kepuasan mahasiswa atas dasar item-item layanan yang dianggap signifikan tersebut.

Penelitian ini menggunakan Metoda Kano dan Taguchi untuk mengidenfikasi jenis layanan pendidikan dan non pendidikan yang dianggap signifikan untuk peningkatan kepuasan mahasiswa dan memberikan rekomendasi perbaikan. Terdapat beberapa penelitian yang telah membahas pengukuran kepuasan pelanggan dengan menggunakan Metoda Kano dan Taguchi. Salah satunya adalah penelitian dari Arash Shahin dan Nasibeh Janatyan dari Iran pada tahun 2015 yang menggunakan Metode Kano dan Taguchi untuk mengukur index kepuasan mahasiswa pada sebuah universitas dengan jumlah sampel 30 responden. Penelitian lain yang menggunakan Metode Taguchi pada kepuasan mahasiswa yaitu dari Roma Mitra Debnath, et al pada tahun 2011 yang berjudul Emerging Trend of Customer Satisfaction in academic Process an Application SPC and Taguchi's Robust Parameter Design. Selain menggunakan Taguchi, penelitian ini juga menggunakan Statictical Process Control (SPC) untuk mengukur kepuasan mahasiswa (Debnath, 2011). Dalam penelitian ini, Metode Kano akan digunakan mengelompokkan item-item layanan apa saja yang dianggap signfikan untuk meningkatkan kepuasan mahasiswa, yaitu item-item layanan yang termasuk kategori one-dimensional dan attractive (Berger, et al., 1993). Adapun Metode Taguchi digunakan untuk memverifikasi hasil pengelompokan dari Metode Kano sehingga diperoleh hasil yang lebih optimal dan mengurutkan prioritas perbaikan dari item-item layanan yang termasuk dalam kelompok attractive dan one-dimentional. Hasil dari yang diperoleh dari Metode Taguchi dapat memudahkan pihak Fakultas Teknik UNDIP untuk memprioritaskan item-item layanan apa yang akan diperbaiki kualitasnya terlebih dahulu.

\section{TINJAUAN PUSTAKA Metode Kano}

Metode Kano adalah metode yang memiliki tujuan untuk mengategorikan item-item layanan yang digunakan berdasarkan seberapa baik item-item layanan tersebut dalam memuaskan kebutuhan pelanggan. Terdapat 5 kategori dalam Metode Kano yang digunakan untuk mengelompokkan item layanan (Szymczak \& Kowal, 2016): 
a. Must-be, item layanan yang termasuk dalam kategori ini tidak menjadi perhatian khusus bagi konsumen, namun apabila item layanan tersebut tidak terpenuhi akan memberikan efek yang sangat negatif terhadap kepuasan konsumen.

b. One-Dimensional, dalam kategori ini tingkat kepuasan konsumen berhubungan linier dengan kinerja suatu item layanan, sehingga akan memberikan efek positif apabila kinerja item layanan tersebut tinggi.

c. Attractive, tingkat kepuasan pelanggan akan meningkat tinggi dengan meningkatnya kinerja item layanan. Akan tetapi penurunan kinerja item layanan tidak menurunkan tingkat kepuasan konsumen.

d. Indifferent, item layanan yang termasuk dalam kategori ini tidak memberikan efek positif maupun negatif terhadap tingkat kepuasan konsumen.

Analisis kepuasan pelanggan secara kuantatif dapat dilakukan dengan cara menghitung indeks CSI better dan worse untuk mengukur dampak positif dan negatif suatu item layanan terhadap kepuasan konsumen (Berger, et al., 1993). Indeks CSI better dan worse dapat dihitung dengan menggunakan rumus berikut (Szymczak \& Kowal, 2016):

- Customer Satisfaction Index Better (CSIB)

$$
C S I_{B}=\frac{A+O}{A+O+I+M+R}
$$

- Customer Satisfaction Index Worst (CSIW)

$$
C S I_{w}=\frac{O+M}{A+O+I+M+R}
$$

\section{Metode Taguchi}

Metode Taguchi menyediakan informasi yang membantu pihak manajemen dalam membuat suatu kebijakan (Ho, Feng, \& Yen, 2013). Metode Taguchi juga dapat dilakukan pada bidang jasa menggunakan nilai S/N rasio dan matriks OA $\mathrm{L}_{12}$ (Raajpot, Javed, \& Koh, 2008). Dalam perancangan kualitas, Metode Taguchi mengembangkan konsep $\mathrm{S} / \mathrm{N}$ rasio untuk eksperimen yang melibatkan sejumlah faktor atau item. $\mathrm{S} / \mathrm{N}$ rasio diformulasikan agar peneliti dapat memilih nilai level item terbesar untuk mengoptimalkan karakteristik kualitas dari suatu eksperimen. Taguchi merekomendasikan tiga karakteristik kualitas dari S/N rasio, yaitu (Soejanto, 2009): e. Reverse, item layanan yang termasuk dalam kategori ini harus dihindari untuk mendapatkan kepuasan konsumen.

Pengelompokkan jawaban responden dalam salah satu kategori pada Metode Kano dilakukan dengan mengevalusi jawaban responden atas pernyataan functional dan disfunctional sebagaimana ketentuan yang terdapat dalam Tabel 1. Selanjutnya, setelah dilakukan pengelompokkan, penentuan kelompok untuk setiap item layanan dilakukan dengan menggunakan Blauth's formula.

- Jika (One-Dimensional + Attractive + Must be) > (Indifferent + Reverse + Questionable) maka grade diperoleh dari yang paling maksimum dari One-Dimensional, Attractive, dan Must be.

- Jika (One-Dimensional + Attractive + Must be) (Indifferent + Reverse + Questionable) maka grade diperoleh dari yang paling maksimum dari Indifferent, Reverse, dan Questionable.

1. Smaller the Better

Pada karakteristik kualitas ini, karakteristk kualitas adalah kontinu dan tidak negatif, dan nilai yang diinginkan adalah 0 . Sehingga karakteristik kualitas ini digunakan untuk permasalahan semakin kecil, semakin baik.

$$
S N R=-10 \log _{10}\left[\frac{1}{n} \sum_{i=1}^{n} y_{i}^{2}\right]
$$

\section{Nominal the Better}

Jenis permasalahan pada karakteristik kualitas ini adalah tertuju pada nilai tertentu, karakteristik kualitasnya kontinu dan non negatif, yaitu nilai 0 hingga tak terhingga. Nilai targetnya tidak nol dan terbatas.

3. Larger the Better

$$
S N R=10 \log _{10}\left[\frac{\mu^{2}}{\sigma^{2}}\right]
$$

Disini karakteristik kualitas adalah kontinu, non negatif, dan dapat mengambil nilai dari 0 hingga nilai tak terhingga. Nilai targetnya adalah sebesar mungkin. Sehingga karakteristik kualitas ini digunakan untuk permasalahan semakin besar, semakin baik.

$$
S N R=-10 \log _{10}\left[\frac{1}{n} \sum_{i=1}^{n} \frac{1}{y_{i}^{2}}\right]
$$

Tabel 1. Tabel Evaluasi Kano

\begin{tabular}{ccccccc}
\hline \multirow{2}{*}{ Kebutuhan Konsumen } & \multicolumn{6}{c}{ Disfunctional } \\
\cline { 2 - 7 } & Suka & Harap & Netral & Toleransi & Tidak Suka \\
\hline \multirow{2}{*}{} & Suka & $\mathrm{Q}$ & $\mathrm{A}$ & $\mathrm{A}$ & $\mathrm{A}$ & $\mathrm{O}$ \\
\cline { 2 - 7 } & Harap & $\mathrm{R}$ & $\mathrm{I}$ & $\mathrm{I}$ & $\mathrm{I}$ & $\mathrm{M}$ \\
\cline { 2 - 7 } & Netral & $\mathrm{R}$ & $\mathrm{I}$ & $\mathrm{I}$ & $\mathrm{I}$ & $\mathrm{M}$ \\
\cline { 2 - 7 } & Toleransi & $\mathrm{R}$ & $\mathrm{I}$ & $\mathrm{I}$ & $\mathrm{I}$ & $\mathrm{M}$ \\
\cline { 2 - 7 } & Tidak Suka & $\mathrm{R}$ & $\mathrm{R}$ & $\mathrm{R}$ & $\mathrm{R}$ & $\mathrm{Q}$ \\
\hline
\end{tabular}


Dalam Metode Taguchi pemilihan matriks ortogonal array (OA) yang sesuai diperlukan untuk menggambarkan jumlah item, level, dan pengamatan yang akan dilakukan. Penentuan matriks OA dilakukan dengan menentukan terlebih dahulu derajat kebebasan dari suatu penelitian penelitian. Dalam hal ini, penentuan derajat kebebasan dapat dilakukan dengan rumus sebagai berikut (Shahin \& Nasibeh, 2015):

$$
\mathrm{A}(\mathrm{nA}-1)+\mathrm{B}(\mathrm{nB}-1)+(\mathrm{nA}-1)(\mathrm{nB}-1)+1
$$

Rumus di atas digunakan apabila terdapat dua item dengan satu interaksi antara item A dan B, dimana A dan B merupakan jumlah item A dan B, sedangkan nA dan $\mathrm{nB}$ merupakan level dari item A dan B. Apabila tidak terdapat interaksi, derajat kebebasan dihitung dengan rumus berikut (Soejanto, 2009):

$$
\text { (Jumlah Item) x (Level Item - 1) }
$$

\section{METODE PENELITIAN \\ Variabel dan Item-item Pernyataan}

Variabel dan item-item pernyataan yang digunakan dalam penelitian ini dapat dilihat pada Tabel 2. Sejumlah variabel dan item-item penyataan yang digunakan dalam penelitian ini mengacu pada penelitian terdahulu, seperti pada penelitian yang dilakukan oleh Cheruiyot \& Maru (2013) dan Gabriel dkk (2016).

\section{Responden Penelitian}

Terdapat dua kelompok responden yang digunakan dalam penelitian ini, yaitu kelompok responden untuk pengisian kuesioner pada Metode Kano dan kelompok responden untuk pengisian kueisoner pada Metode Taguchi. Terdapat 120 responden yang berpartisipasi untuk mengisi kuesioner pada Metode Kano. Kemudian 120 sampel tersebut dibagi secara proporsional ke setiap jurusan dengan pembulatan perhitungan ke atas. Jumlah reponden untuk pengisian kuesioner pada Metode Taguchi dilakukan dengan menentukan terlebih dahulu matriks OA yang akan digunakan berdasarkan jumlah item dan level item yang didapatkan dari hasil pengolahan kuesioner dengan menggunakan Metode Kano. Jumlah item sama dengan jumlah item-item layanan yang termasuk ke dalam kategori one-dimensional $(\mathrm{O})$ dan attractive (A); sedangkan jumlah level item yang digunakan hanya dua yaitu one-dimensional dan attractive karena kedua kategori tersebut dapat memberikan efek positif terhadap kepuasan pelanggan (Berger, et al., 1993). Selanjutnya, jumlah sampel yang diambil disesuaikan dengan runs dan replikasi yang digunakan pada matriks OA yang terpilih (Shahin \& Nasibeh, 2015).

\section{Teknik Pengumpulan Data}

Pengumpulan data dilakukan dengan dua cara, yaitu wawancara dan survei. Wawancara dilakukan untuk menggali informasi-informasi tentang kesesuaian atas item-item layanan yang dalam penelitian ini dengan layanan pendidikan dan nonpendidikan di lingkungan Fakultas Teknik UNDIP. Dalam hal ini, wawancara dilakukan kepada Dekan Fakultas Teknik. Adapun teknik pengumpulan data dengan survei dilakukan dengan menyebarkan kuesioner kepada sejumlah responden. Terdapat dua jenis kuesioner yang digunakan (Kuesioner untuk Kano dan Kuesioner untuk Taguchi) dan kedua jenis kuesioner tersebut merupakan kuesioner tertutup, dimana responden hanya memberikan penilaian dengan rentang tertentu kepada setiap pernyataan.

Teknik sampling yang digunakan untuk memilih responden yang akan mengisi kuesioner adalah Stratified Random Sampling. Berdasarkan teknik tersebut, seluruh popoulasi penelitian yaitu seluruh mahasiswa Fakultas Teknik akan dikelompokkan menjadi sejumlah sub-populasi. Dalam hal ini, yang dijadikan sebagai sub-populasi adalah jurusan-jurusan yang terdapat pada pada Fakultas Teknik. Dengan demikian terdapat 12 sub-populasi. Selanjutnya, penentuan jumlah sampel pada setiap sub-populasi dilakukan secara proporsional dan pemilihan seorang responden dari setiap sub-populasi dilakukan secara random.

\section{Teknik Pengolahan Data}

Pengolahan data yang digunakan pada penelitian ini menggunakan pendekatan kulitatif, sehingga perlu dilakukan uji validitas dan uji reliabilitas baik pada kuesioner untuk Metode Kano maupun untuk kuesioner untuk Metode Taguchi. Uji validitas digunakan untuk mengetahui apakah suatu item pernyataan mampu untuk mengungkapkan sesuatu yang akan diukur oleh kuesioner tersebut. Uji ini dilakukan dengan membandingkan nilai Corrected Item-Total Correlation (r-hitung) dari setiap item pernyatan dalam kuesioner dengan nilai r-tabel. Suatu item pernyataan dikatakan valid apabila r-hitung lebih besar dari nilai r-tabel. Selanjutnya, uji reliabilitas digunakan untuk mengetahui konsistensi dari kuesioner sebagai alat ukur. Pengujian reliabilitas menggunakan nilai Alpha Cronbach. Menurut Arikunto (1998), suatu kuesioner dikatakan memiliki reliabilitas yang baik apabila memiliki nilai Alpha Cronbach lebih besar dari 0,6. Setelah semua item penyataan valid dan reliabel, kemudian dilakukan pengolahan data dengan menggunakan Metode Kano dan Metode Taguchi. Dalam hal ini, Metode Taguchi yang digunakan untuk perancangan eksperiman untuk jasa memiliki langkah-langkah yang hampir sama dengan Metode Taguchi yang digunakan untuk perancangan eksperiman untuk produk barang (Kumar, Motwani, \& Otero, 1996).

\section{HASIL DAN PEMBAHASAN}

Hasil Evaluasi Layanan di Fakultas Teknik dengan Menggunakan Metode Kano

Sebelum melakukan pengolahan data dengan menggunakan Metode Kano, pengujian validasi 
dilakukan pada setiap item pernyataan yang terdapat pada kuesioner functional maupun disfunctional. Pada penelitian ini, jumlah responden yang digunakan untuk uji validitas dan reliabilitas (pilot study) hanya 50 orang dan tingkat signifikansi yang digunakan adalah 0,05, sehihgga nilai $r$ tabel-nya adalah 0,2353.

Berdasarkan hasil uji validitas, didapatkan bahwa seluruh item pernyataan pada kuesioner bagian functional maupun disfunctional memiliki nilai rhitung lebih besar dari r-tabel. Dapat disimpulkan bahwa seluruh item pernyataan valid sehingga dapat digunakan untuk mengukur kualitas layanan pendidikan dan non pendidikan yang diberikan oleh Fakultas Teknik UNDIP. Selanjutnya, pengujian reliabilitas dilakukan dengan menggunakan nilai Alpha Cronbach. Berdasarkan hasil pengujian reliabilitas, didapatkan nilai Cronbach's Alpha lebih dari 0,6; sehingga, dapat dikatakan bahwa kuesioner yang digunakan dalam penelitian ini reliabel dan dapat dilakukan penyebaran kuesioner sesuai dengan target jumlah responden dan hasilnya dapat diolah dengan Metode Kano.

Selanjutnya, hasil pengolahan jawaban-jawaban dari kuesioner dengan menggunakan Metode Kano menunjukkan bahwa terdapat 6 item layanan yang termasuk dalam kategori one-dimensional, 2 item layanan yang termasuk dalam kategori attractive, 7 item layanan yang termasuk dalam kategori must-be, serta 13 item layanan yang termasuk dalam kategori indifferent. Secara rinci, hasil evaluasi layanan di Fakultas Teknik dengan mengggunakan Metode Kano dapat dilihat pada Tabel 3.

Berdasarkan hasil perhitungan yang ditunjukkan pada Tabel 3, item layanan yang memiliki nilai $\mathrm{CSI}_{\mathrm{B}}$ paling tinggi adalah item layanan TU3 (kemudahan akses jalan menuju kampus, nilai $\mathrm{CSI}_{\mathrm{B}}=0,567$ ); diiikuti oleh item layanan EM3, NP1, dan RL2. Adapun item layanan yang memiliki nilai $\mathrm{CSI}_{\mathrm{W}}$ terendah adalah item layanan EM1 (kemudahan mengakses informasi mengenai akademik, nilai $\mathrm{CSI}_{\mathrm{w}}=$ 0,580), diikuti oleh item layanan NP2, TB1, dan TB2.

Dalam hal ini Metode Kano tidak memberikan prioritas; mana diantara kedelepan item layanan tersebut yang harus diperbaiki terlebih dahulu. Baik item layanan yang memiliki $\mathrm{CSI}_{\mathrm{B}}$ tertinggi maupun $\mathrm{CSI}_{\mathrm{w}}$ terendah sama-sama memiliki peluang untuk menjadi prioritas. Meningkatkan $\mathrm{CSI}_{\mathrm{B}}$ yang sudah baik berpeluang untuk memberikan kepuasan yang signifikan bagi mahasiwa; demikian juga, meningkatkan CSIw yang masih buruk berpeluang untuk untuk meningkatkan kepuasan mahasiswa secara signifikan.

Berdasarkan hal ini, langkah selanjutnya adalah memilih item layanan yang akan diprioritaskan untuk ditingkatkan dengan menggunakan Metode Taguchi.

\section{Hasil Evaluasi Layanan di Fakultas Teknik dengan Menggunakan Metoda Taguchi}

Jumlah sampel yang dibutuhkan pada Metode Taguchi ditentukan dari runs dan replikasi yang digunakan pada matriks OA yang terpilih. Didapatkan bahwa matriks $\mathrm{Oa}$ yang terpilih yaitu $\mathrm{L}_{12}\left(2^{11}\right)$ karena memiliki derajat kebebasan lebih tinggi dibandingkan dengan derajat kebebasan penelitian. Matriks OA tersebut memiliki 12 kali runs, sehingga apabila menggunakan replikasi 5 kali pada setiap eksperimennya, maka jumlah sampel yang dibutuhkan adalah 60 responden. Kuesioner pada Metode Taguchi hanya terdiri dari item-item layanan yang termasuk dalam kategori one-dimensional dan attractive saja. Selanjutnya, pernyataan dari item-item layanan yang termasuk dalam kategori one-dimensional dan attractive disusun sedemikian rupa berdasarkan kombinasi matriks OA sebagaimana tampak pada Tabel 4.

Sebagaimana pada Metode Kano, sebelum dilakukan pengolahan data, indikator-indikator penyataan pada kuesioner dari Metode Taguchi diuji validitas dan reliabilitas terlebih dahulu. Pengujian validitas dan reliabilitas untuk kuesioner Metode Taguchi dilakukan hanya kepada 60 responden. Dalam hal ini, 30 respneden akan digunakan untuk menguji penyataan-pernyataan pada level one-dimensional dan 30 responden akan diigunakan untuk menguji pernyataan-pernyataan pada level attractive. Berdasarkan jumlah responden dan tingkat signifikansi yang digunakan yaitu 0,05 , diperoleh nilai r-tabel sebesar 0,3061.

Hasil pengujian validitas menunjukkan bahwa semua item pernyataan memiliki

nilai r-hitung lebih besar dari r-tabel. Hal ini menunjukkan bahwa seluruh item penyataan yang digunakan sudah valid. Selanjutnya, berdasarkan hasil uji reliabilitas, diketahui bahwa kedua level item (onedimensional dan attractive) memiliki nilai Cronbach's Alpha lebih dari 0,6, sehingga dapat dikatakan bahwa kedua level item reliabel.

Langkah berikutnya adalah mentransformasikan jawaban responden ke dalam bentuk $\mathrm{S} / \mathrm{N}$ rasio. Pada penelitian ini, karakteristik kualitas yang digunakan untuk menilai $\mathrm{S} / \mathrm{N}$ rasio adalah semakin besar semakin baik (larger the better). Berikut adalah contoh perhitungan $\mathrm{S} / \mathrm{N}$ rasio pada pada runs pertama.

$$
\begin{aligned}
\mathrm{S} / \mathrm{N} \text { rasio }= & 10 \log 10((1 / 5) \times(1 / 4,382+1 / 4,52 \\
& +1 / 3,252+1 / 4,752+1 / 3,52))=-11,91
\end{aligned}
$$

Secara rinci, hasil perhitungan replikasi yang berasal rata-rata jawaban tiap responden dan perhitungan $\mathrm{S} / \mathrm{N}$ rasio dengan karakteriktik kualitas larger the better dapat dilihat pada Tabel 5. Replikasi merupakan ratarata jawaban responden terhadap pernyataanpernyataan yang diajukan dengan dengan menggunakan skala likert 1-5 
Tabel 2. Definisi Operasional Variabel

\begin{tabular}{|c|c|c|c|c|}
\hline $\begin{array}{c}\text { Variabel } \\
\text { Konstruk }\end{array}$ & $\begin{array}{c}\text { Definisi Variabel } \\
\text { Konstruk }\end{array}$ & $\begin{array}{l}\text { Dimensi } \\
\text { Variabel }\end{array}$ & Item Pernyataan & Kode \\
\hline \multirow{24}{*}{$\begin{array}{l}\text { Kualitas } \\
\text { Layanan }\end{array}$} & \multirow{24}{*}{$\begin{array}{l}\text { Kualitas layanan adalah } \\
\text { upaya pemenuhan } \\
\text { kebutuhan yang } \\
\text { dibarengi dengan } \\
\text { keinginan pelanggan } \\
\text { serta ketepatan cara } \\
\text { penyampaiannya agar } \\
\text { dapat memenuhi harapan } \\
\text { dan kepuasan pelanggan } \\
\text { tersebut (Tjiptono \& } \\
\text { Chandra, 2004) }\end{array}$} & \multirow{4}{*}{$\begin{array}{l}\text { Tangible Fasilitas } \\
\text { Proses Belajar } \\
\text { Mengajar } \\
\text { (Penampilan fisik dari } \\
\text { pelayanan jasa) }\end{array}$} & Fasilitas ruang kelas yang memadai (Cheruiyot \& Maru, 2013) & TB1 \\
\hline & & & $\begin{array}{l}\text { Perpustakaan menyediakan buku dan jurnal yang berhubungan dengan bidangnya masing-masing (Cheruiyot \& Maru, } \\
\text { 2013) }\end{array}$ & TB2 \\
\hline & & & Ruang diskusi bagi mahasiswa (Dilengkapi akses internet, nyaman, dll.) & TB3 \\
\hline & & & Tersedianya spot wifi pada Fakultas Teknik (Cheruiyot \& Maru, 2013) & TB4 \\
\hline & & \multirow{4}{*}{$\begin{array}{l}\text { Tangible Fasilitas } \\
\text { Umum }\end{array}$} & Toilet umum bersih dan nyaman & TU1 \\
\hline & & & Fasilitas untuk olahraga (Cheruiyot \& Maru, 2013) & TU2 \\
\hline & & & $\begin{array}{l}\text { Kemudahan akses jalan menuju kampus bagi mahasiswa (tersedianya angkutan umum, kondisi jalan yang baik walapun } \\
\text { saat kondisi hujan) }\end{array}$ & TU3 \\
\hline & & & Tempat parkir untuk mahasiswa di area kampus (Cheruiyot \& Maru, 2013) & TU4 \\
\hline & & \multirow{4}{*}{$\begin{array}{l}\text { Reliability } \\
\text { (Kemampuan untuk } \\
\text { memberikan } \\
\text { pelayanan dengan } \\
\text { handal dan akurat) }\end{array}$} & $\begin{array}{l}\text { Dosen mengajar sesuai dengan kontrak kuliah yang telah diberikan kepada mahasiswa saat pertemuan pertama mata } \\
\text { kuliah (Cheruiyot \& Maru, 2013) }\end{array}$ & RL1 \\
\hline & & & Komunikasi antara dosen dan mahasiswa saat di kelas berjalan baik (Cheruiyot \& Maru, 2013) & RL2 \\
\hline & & & Terdapat keseimbangan antara teori dan praktik pada mata kuliah (Cheruiyot \& Maru, 2013) & RL3 \\
\hline & & & Hasil nilai ujian selalu diumumkan tepat waktu (Cheruiyot \& Maru, 2013) & RL4 \\
\hline & & \multirow{4}{*}{$\begin{array}{l}\text { Responsiveness } \\
\text { (Respon atau } \\
\text { kesigapan karyawan } \\
\text { dalam membantu } \\
\text { pelanggan) }\end{array}$} & Staff fakultas dan jurusan melayani mahasiswa dengan sopan (Cheruiyot \& Maru, 2013) & RS1 \\
\hline & & & Staff fakultas dan jurusan membantu mahasiswa secara cepat dan tepat (Cheruiyot \& Maru, 2013) & RS2 \\
\hline & & & Staff fakultas dan jurusan selalu dapat ditemui pada jam kerja (Cheruiyot \& Maru, 2013) & RS3 \\
\hline & & & $\begin{array}{l}\text { Pihak jurusan pernah menyediakan waktu khusus dengan mahasiswa (forum) untuk menyampaikan keluhan unit kerja } \\
\text { jurusan (Cheruiyot \& Maru, 2013) }\end{array}$ & RS4 \\
\hline & & \multirow{4}{*}{$\begin{array}{l}\text { Assurance } \\
\text { (Kemampuan } \\
\text { karyawan atas } \\
\text { pengetahuan terhadap } \\
\text { jasa layanan secara } \\
\text { tepat dan memberikan } \\
\text { keamanan di dalam } \\
\text { memanfaatkan jasa) }\end{array}$} & Staff fakultas dan jurusan memiliki pengetahuan yang lebih mengenai bidang pekerjaannya (Cheruiyot \& Maru, 2013) & AS1 \\
\hline & & & Staff fakultas dan jurusan memiliki kemampuan yang relevan terhadap tugas mereka (Cheruiyot \& Maru, 2013) & AS2 \\
\hline & & & Mahasiswa merasa yakin mengenai apa yang disampaikan dosen maupun staff (Cheruiyot \& Maru, 2013) & AS3 \\
\hline & & & Mahasiswa selalu merasa aman saat berada di lingkungan kampus (Cheruiyot \& Maru, 2013) & AS4 \\
\hline & & \multirow{4}{*}{$\begin{array}{l}\text { Emphaty (Perhatian } \\
\text { secara individual yang } \\
\text { diberikan perusahaan } \\
\text { kepada pelanggan) }\end{array}$} & $\begin{array}{l}\text { Mahasiswa dapat memperoleh informasi yang berkaitan dengan akademik dengan mudah, baik melalui web } \\
\text { (www.sia.undip.ac.id dan www. ft.undip.ac.id) maupun dari staff tata usaha (Cheruiyot \& Maru, 2013) }\end{array}$ & E1 \\
\hline & & & $\begin{array}{l}\text { Staff fakultas dan jurusan selalu mendengarkan keluhan mahasiswa mengenai proses akademik (Cheruiyot \& Maru, } \\
\text { 2013) }\end{array}$ & E2 \\
\hline & & & $\begin{array}{l}\text { Staff fakultas dan jurusan bekerja dengan sepenuhnya untuk memahami dan membantu permasalahan mahasiswa } \\
\text { mengenai proses akademik (Cheruiyot \& Maru, 2013) }\end{array}$ & E3 \\
\hline & & & Dosen dan staff fakultas maupun jurusan selalu mudah untuk dihubungi (Cheruiyot \& Maru, 2013) & E4 \\
\hline \multirow{4}{*}{$\begin{array}{l}\text { Nilai } \\
\text { Pelanggan }\end{array}$} & \multirow{4}{*}{$\begin{array}{l}\text { Nilai pelanggan ialah } \\
\text { selisih antara total nilai } \\
\text { tambah yang diperoleh } \\
\text { konsumen dibandingkan } \\
\text { dengan total biaya yang } \\
\text { dikeluarkan (Buchari, } \\
\text { 2009). }\end{array}$} & \multirow[b]{4}{*}{ Nilai Pelanggan } & Kualitas layanan yang diberikan sesuai dengan biaya yang dikeluarkan mahasiswa (Gabriel, Eric, \& Dorion, 2016) & NP1 \\
\hline & & & Metode pembayaran kuliah selalu dapat dilakukan dengan mudah (Gabriel, Eric, \& Dorion, 2016) & NP2 \\
\hline & & & Terdapat penjaminan mutu pada proses belajar mengajar di Fakultas Teknik & NP3 \\
\hline & & & Pihak Fakultas Teknik memberikan jaminan pelayanan yang baik & NP4 \\
\hline
\end{tabular}

J@ti Undip: Jurnal Teknik Industri, Vol. 13, No. 1, Januari 2018 
Tabel 3. Hasil Evaluasi Layanan di Fakultas Teknik dengan Mengggunakan Metode Kano

\begin{tabular}{|c|c|c|c|c|c|c|c|c|c|c|c|}
\hline Item & $\mathbf{O}$ & $\mathbf{A}$ & $\mathbf{M}$ & I & $\mathbf{R}$ & $\mathbf{Q}$ & $\mathrm{O}+\mathrm{A}+\mathrm{M}$ & $\mathbf{I}+\mathbf{R}+\mathbf{Q}$ & Grade & $C S I_{B}$ & $C S I_{W}$ \\
\hline TB1 & 47 & 18 & 29 & 37 & 7 & 4 & 94 & 48 & $\mathrm{O}$ & 0,471 & $-0,551$ \\
\hline TB2 & 32 & 18 & 22 & 63 & 3 & 4 & 72 & 70 & $\mathrm{O}$ & 0,362 & $-0,391$ \\
\hline TB3 & 22 & 9 & 41 & 51 & 14 & 5 & 72 & 70 & $\mathrm{M}$ & 0,226 & $-0,460$ \\
\hline TB4 & 8 & 15 & 24 & 62 & 19 & 14 & 47 & 95 & $\mathrm{I}$ & 0,180 & $-0,250$ \\
\hline TU1 & 28 & 7 & 37 & 45 & 15 & 10 & 72 & 70 & $\mathrm{M}$ & 0,265 & $-0,492$ \\
\hline TU2 & 11 & 10 & 22 & 87 & 9 & 3 & 43 & 99 & I & 0,151 & $-0,237$ \\
\hline TU3 & 24 & 56 & 7 & 53 & 1 & 1 & 87 & 55 & A & 0,567 & $-0,220$ \\
\hline TU4 & 26 & 10 & 47 & 39 & 15 & 5 & 83 & 59 & $\mathrm{M}$ & 0,263 & $-0,533$ \\
\hline RL1 & 23 & 21 & 22 & 70 & 3 & 3 & 66 & 76 & $\mathrm{I}$ & 0,317 & $-0,324$ \\
\hline RL2 & 29 & 26 & 25 & 59 & 1 & 2 & 80 & 62 & $\mathrm{O}$ & 0,393 & $-0,386$ \\
\hline RL3 & 13 & 21 & 28 & 72 & 5 & 3 & 62 & 80 & $\mathrm{I}$ & 0,245 & $-0,295$ \\
\hline RL4 & 12 & 14 & 23 & 83 & 4 & 6 & 49 & 93 & $\mathrm{I}$ & 0,191 & $-0,257$ \\
\hline RS1 & 29 & 18 & 33 & 52 & 6 & 4 & 80 & 62 & $\mathrm{M}$ & 0,341 & $-0,449$ \\
\hline RS2 & 21 & 11 & 39 & 62 & 5 & 4 & 71 & 71 & I & 0,232 & $-0,435$ \\
\hline RS3 & 23 & 23 & 27 & 62 & 4 & 3 & 73 & 69 & $\mathrm{M}$ & 0,331 & $-0,360$ \\
\hline RS4 & 24 & 21 & 25 & 64 & 5 & 3 & 70 & 72 & $\mathrm{I}$ & 0,324 & $-0,353$ \\
\hline AS1 & 25 & 17 & 29 & 68 & 0 & 3 & 71 & 71 & $\mathrm{I}$ & 0,302 & $-0,388$ \\
\hline AS2 & 18 & 14 & 36 & 70 & 1 & 3 & 68 & 74 & $\mathrm{I}$ & 0,230 & $-0,388$ \\
\hline AS3 & 16 & 12 & 25 & 83 & 2 & 4 & 53 & 89 & I & 0,203 & $-0,297$ \\
\hline AS4 & 35 & 10 & 37 & 53 & 5 & 2 & 82 & 60 & $\mathrm{M}$ & 0,321 & $-0,514$ \\
\hline EM1 & 56 & 19 & 24 & 38 & 1 & 4 & 99 & 43 & $\mathrm{O}$ & 0,543 & $-0,580$ \\
\hline EM2 & 22 & 9 & 42 & 61 & 4 & 4 & 73 & 69 & $\mathrm{M}$ & 0,225 & $-0,464$ \\
\hline EM3 & 44 & 29 & 26 & 39 & 1 & 3 & 99 & 43 & $\mathrm{O}$ & 0,525 & $-0,504$ \\
\hline Em4 & 12 & 10 & 37 & 75 & 3 & 5 & 59 & 83 & $\mathrm{I}$ & 0,161 & $-0,358$ \\
\hline NP1 & 23 & 46 & 18 & 48 & 3 & 4 & 87 & 55 & A & 0,500 & $-0,297$ \\
\hline NP2 & 43 & 29 & 34 & 31 & 2 & 3 & 106 & 36 & $\mathrm{O}$ & 0,518 & $-0,554$ \\
\hline NP3 & 16 & 7 & 38 & 74 & 3 & 4 & 61 & 81 & I & 0,167 & $-0,391$ \\
\hline NP4 & 20 & 7 & 43 & 62 & 6 & 4 & 70 & 72 & I & 0,196 & $-0,457$ \\
\hline
\end{tabular}

Tabel 4. Matriks Ortogonal Array Penelitian

\begin{tabular}{|c|c|c|c|c|c|c|c|c|}
\hline \multirow{2}{*}{ Eksperimen } & \multicolumn{8}{|c|}{ Item } \\
\hline & TB1 & TB2 & TU3 & RL2 & E1 & $\mathbf{E 3}$ & NP1 & NP2 \\
\hline 1 & $\mathrm{O}$ & $\mathrm{O}$ & $\mathrm{O}$ & $\mathrm{O}$ & $\mathrm{O}$ & $\mathrm{O}$ & $\overline{\mathrm{O}}$ & $\mathrm{O}$ \\
\hline 2 & $\mathrm{O}$ & $\mathrm{O}$ & $\mathrm{O}$ & $\mathrm{O}$ & $\mathrm{O}$ & $\mathrm{A}$ & $\mathrm{A}$ & $\mathrm{A}$ \\
\hline 3 & $\mathrm{O}$ & $\mathrm{O}$ & A & A & A & $\mathrm{O}$ & $\mathrm{O}$ & $\mathrm{O}$ \\
\hline 4 & $\mathrm{O}$ & $\mathrm{A}$ & $\mathrm{O}$ & A & $\mathrm{A}$ & $\mathrm{O}$ & A & A \\
\hline 5 & $\mathrm{O}$ & $\mathrm{A}$ & A & $\mathrm{O}$ & $\mathrm{A}$ & $\mathrm{A}$ & $\mathrm{O}$ & $\mathrm{A}$ \\
\hline 6 & $\mathrm{O}$ & A & $\mathrm{A}$ & A & $\mathrm{O}$ & $\mathrm{A}$ & $\mathrm{A}$ & $\mathrm{O}$ \\
\hline 7 & A & $\mathrm{O}$ & A & A & $\mathrm{O}$ & $\mathrm{O}$ & $\mathrm{A}$ & A \\
\hline 8 & A & $\mathrm{O}$ & $\mathrm{A}$ & $\mathrm{O}$ & $\mathrm{A}$ & $\mathrm{A}$ & $\mathrm{A}$ & $\mathrm{O}$ \\
\hline 9 & A & $\mathrm{O}$ & $\mathrm{O}$ & A & A & A & $\mathrm{O}$ & A \\
\hline 10 & A & $\mathrm{A}$ & A & $\mathrm{O}$ & $\mathrm{O}$ & $\mathrm{O}$ & $\mathrm{O}$ & A \\
\hline 11 & $\mathrm{~A}$ & $\mathrm{~A}$ & $\mathrm{O}$ & A & $\mathrm{O}$ & $\mathrm{A}$ & $\mathrm{O}$ & $\mathrm{O}$ \\
\hline 12 & A & $\mathrm{A}$ & $\mathrm{O}$ & $\mathrm{O}$ & A & $\mathrm{O}$ & $\mathrm{A}$ & $\mathrm{O}$ \\
\hline
\end{tabular}


Tabel 5. Hasil Perhitungan Kuesioner Taguchi

\begin{tabular}{|c|c|c|c|c|c|c|c|c|c|c|c|c|c|c|}
\hline \multirow{2}{*}{ Runs } & \multicolumn{8}{|c|}{ Indikator } & \multicolumn{5}{|c|}{ Replikasi } & \multirow[b]{2}{*}{ S/N Ratio } \\
\hline & $\overline{T B 1}$ & TB2 & TU3 & RL2 & E1 & $\overline{E 3}$ & NP1 & $\overline{\text { NP2 }}$ & $\overline{1}$ & 2 & 3 & 4 & 5 & \\
\hline 1 & $\mathrm{O}$ & $\mathrm{O}$ & $\mathrm{O}$ & $\mathrm{O}$ & $\mathrm{O}$ & $\mathrm{O}$ & $\mathrm{O}$ & $\mathrm{O}$ & 4,38 & 4,50 & 3,25 & 4,75 & 3,50 & 11,91 \\
\hline 2 & $\mathrm{O}$ & $\mathrm{O}$ & $\mathrm{O}$ & $\mathrm{O}$ & $\mathrm{O}$ & $\mathrm{A}$ & $\mathrm{A}$ & $\mathrm{A}$ & 4,75 & 3,75 & 4,38 & 3,63 & 2,00 & 10,05 \\
\hline 3 & $\mathrm{O}$ & $\mathrm{O}$ & A & A & A & $\mathrm{O}$ & $\mathrm{O}$ & $\mathrm{O}$ & 4,50 & 3,38 & 4,88 & 3,50 & 3,75 & 11,78 \\
\hline 4 & $\mathrm{O}$ & A & $\mathrm{O}$ & A & A & $\mathrm{O}$ & A & A & 3,00 & 3,38 & 2,88 & 2,25 & 3,63 & 9,26 \\
\hline 5 & $\mathrm{O}$ & $\mathrm{A}$ & $\mathrm{A}$ & $\mathrm{O}$ & $\mathrm{A}$ & $\mathrm{A}$ & $\mathrm{O}$ & $\mathrm{A}$ & 3,63 & 3,00 & 4,38 & 3,63 & 4,50 & 11,37 \\
\hline 6 & $\mathrm{O}$ & A & A & A & $\mathrm{O}$ & A & A & $\mathrm{O}$ & 5,00 & 3,75 & 4,88 & 3,38 & 3,13 & 11,63 \\
\hline 7 & A & $\mathrm{O}$ & A & A & $\mathrm{O}$ & $\mathrm{O}$ & A & A & 3,75 & 2,50 & 3,00 & 3,25 & 3,63 & 9,89 \\
\hline 8 & $\mathrm{~A}$ & $\mathrm{O}$ & $\mathrm{A}$ & $\mathrm{O}$ & $\mathrm{A}$ & $\mathrm{A}$ & $\mathrm{A}$ & $\mathrm{O}$ & 3,50 & 3,50 & 3,13 & 2,75 & 2,88 & 9,84 \\
\hline 9 & $\mathrm{~A}$ & $\mathrm{O}$ & $\mathrm{O}$ & A & A & A & $\mathrm{O}$ & $\mathrm{A}$ & 3,13 & 4,63 & 3,38 & 3,13 & 4,13 & 10,99 \\
\hline 10 & A & A & A & $\mathrm{O}$ & $\mathrm{O}$ & $\mathrm{O}$ & $\mathrm{O}$ & A & 4,00 & 3,13 & 3,75 & 4,00 & 3,00 & 10,87 \\
\hline 11 & $\mathrm{~A}$ & $\mathrm{~A}$ & $\mathrm{O}$ & $\mathrm{A}$ & $\mathrm{O}$ & $\mathrm{A}$ & $\mathrm{O}$ & $\mathrm{O}$ & 4,25 & 3,38 & 3,00 & 3,75 & 4,13 & 11,14 \\
\hline 12 & $\mathrm{~A}$ & $\mathrm{~A}$ & $\mathrm{O}$ & $\mathrm{O}$ & A & $\mathrm{O}$ & $\mathrm{A}$ & $\mathrm{O}$ & 3,13 & 3,25 & 3,00 & 3,88 & 2,38 & 9,57 \\
\hline
\end{tabular}

Tabel 6. Perhitungan Main Effect S/N Rasio

\begin{tabular}{ccccc}
\hline Level & O & A & Delta & Rank \\
\hline TB1 & 11 & 10,38 & 0,62 & 2 \\
\hline TB2 & 10,74 & 10,64 & 0,1 & 8 \\
\hline TU3 & 10,49 & 10,9 & 0,41 & 7 \\
\hline RL2 & 10,6 & 10,78 & 0,18 & 4 \\
\hline E1 & 10,92 & 10,47 & 0,45 & 6 \\
\hline E3 & 10,54 & 10,84 & 0,3 & 1 \\
\hline NP1 & 11,34 & 10,04 & 1,3 & 3 \\
\hline NP2 & 10,98 & 10,4 & 0,58 & 5 \\
\hline
\end{tabular}

Selanjutnya dilakukan perhitungan main effect pada $\mathrm{S} / \mathrm{N}$ rasio yang bertujuan untuk mengidentifikasi pengaruh tiap level item terhadap kepuasan atas layanan yang diberikan oleh Fakultas Teknik UNDIP. Berdasarkan hasil perhitungan tersebut akan didapatkan kombinasi item layanan yang optimal yang termasuk dalam kelompok one-dimensional dan attractive serta urutan prioritas item layanan berdasarkan pengaruhnya kepada kepuasan mahasiswa. Berikut adalah contoh perhitungan main effect pada $\mathrm{S} / \mathrm{N}$ rasio dari item layanan TB1 level $\mathrm{O}$ (One-Dimensional) dan level item A (Attractive).

$\overline{\mathrm{TB1}_{O}}=1 / 6 \times(11,91+10,05+11,78+9,26+11,37+$ $11,63)=11,00$

$\overline{T B 1_{A}}=1 / 6 \times(9,89+9,84+10,99+10,87+11,14+$ $9,57)=10,38$

Secara rinci, hasil pehitungan main effect pada $\mathrm{S} / \mathrm{N}$ rasio untuk setiap item layanan dapat dilihat pada Tabel 6. Dalam hal ini, Tabel 6 menunjukkan itemitem layanan yang termasuk dalam kategori onedimensional dan attractive secara optimal. Terdapat perbedaan antara item layanan yang termasuk kategori one-dimensional dan attractive yang dihasilkan dari pengolahan data dengan Metode Kano dan yang dihasilkan dari pengolahan data dengan Metode Taguchi. Pada hasil pengolahan data dengan menggunakan Metode Taguchi, didapatkan 5 item layanan yang termasuk kategori one-dimensional dan terdapat 3 item layanan dalam kategori attractive. Pada hasil pengolahan data dengan menggunakan
Metode Taguchi, item layanan RL2 dan E3 yang semula berada pada kategori one-dimensional dari hasil pengolahan dengan mengggunakan Metode Kano, berubah menjadi kategori attractive pada Metode Taguchi. Adapun item layanan NP1 yang semula berada pada kategori attractive pada Metode Kano, berubah menjadi kategori one-dimensional pada Metode Taguchi. Item layanan yang termasuk kategori one-dimensional adalah item layanan yang dapat meningkatkan kepuasan mahasiswa, sedangkan item layanan yang termasuk kategori attractive adalah item layanan yang apabila dipenuhi oleh pihak Fakultas Teknik UNDIP maka kepuasan mahasiswa akan meningkat, namun apabila tidak dipenuhi maka kepuasan mahasiswa akan menurun.

\section{Rekomendasi Perbaikan}

Berdasarkan hasil yang diperoleh dari penelitian ini, rekomendasi yang dapat diberikan kepada pihak Fakultas Teknik UNDIP dalam meningkatkan kepuasan mahasiswa antara lain:

- Melakukan perawatan secara berkala terhadap fasilitas pada ruang kelas, seperti pendingin ruangan, meja kursi, LCD, dan papan tulis, agar kondisinya selalu baik.

- Salah satu tantangan bagi perguruan tinggi adalah bagaimana mengintegrasikan data informasi yang berasal dari berbagai sumber (Aldridge \& Rowley, 1998). Sehingga sebaiknya pihak FT UNDIP melakukan perbaikan sistem informasi agar web tidak mengalami gangguan saat mahasiswa mengakses informasi, baik saat $\log$ in maupun saat 
mencari informasi, dan menyediakan informasiinformasi yang dibutuhkan mahasiswa, termasuk prosedur administrasi.

- Perbaikan akses jalan ke kampus bagi agar kondisinya baik walaupun saat hujan.

- Komunikasi yang baik antara dosen dan mahasiswa dapat dilakukan dengan memberikan tugas yang relevan dengan mata kuliah dan menggunakan cara yang menarik, memberikan contoh case study, serta mengadakan kuliah bersama dan mendatangkan pembicara yang relevan dengan bidang mahasiswa (Gruber, Fub, Voss, \& Glaser-Zikuda, 2010).

- Menambah relasi dengan organisasi program beasiswa yang bersedia menambah koleksi buku pada perpustakaan.

Melakukan perbaikan kualitas untuk mengurangi jumlah mahasiswa yang tidak puas bukanlah hal yang mudah, namun hal tersebut berhasil dilakukan maka kepuasan mahasiswa akan meningkat (Douglas, McClelland, \& Davies, 2007).

\section{KESIMPULAN}

Item layanan yang dianggap penting dalam meningkatkan kepuasan mahasiswa terhadap jasa layanan pendidikan dan non-pendidikan pada Fakultas Teknik UNDIP yaitu indikator layanan yang termasuk dalam kategori one-dimensional dan attractive. Berdasarkan hasil pengolahan data dengan menggunakan Metode Kano, terdapat 6 indikator variabel yang termasuk dalam kategori onedimensional dan 2 indikator variabel yang termasuk kategori attractive. Berdasarkan hasil pengolahan data dengan menggunakan Metode Taguchi terdapat 5 item layanan yang termasuk kategori one-dimensional, yaitu fasilitas ruang kelas (TB1), tersedianya buku dan jurnal yang sesuai dengan bidang mahasiswa pada perpusatakaan (TB2), kemudahan mengakses informasi yang berkaitan dengan akademik (E1), kualitas layanan yang sesuai dengan biaya kuliah (NP1), dan kemudahan metode pembayaran kuliah (NP2). Adapun pada kategori attractive terdapat 3 item layanan, yaitu kemudahan akses jalan menuju kampus (TU3), komunikasi yang baik antara dosen dan mahasiswa (RL2), dan dosen dan staf tata usaha dapat membantu mahasiswa selama proses akademik (E3).

Peningkatan kualitas layanan dapat dilakukan oleh pihak Fakultas Teknik Universitas Diponegoro dengan melakukan prioritas terhadap item layanan yang akan ditingkatkan kualitas layanannya secara bertahap. Dalam penelitian ini item layanan yang memiliki pengaruh besar terhadap kepuasan mahasiswa ditunjukkan oleh besarnya selisih dari respon tertinggi dan respon terendah yang dihasilkan oleh item tersebut pada masing-masing levelnya. Selisih tersebut menunjukkan seberapa besar pengaruh faktor tersebut terhadap kepuasan mahasiswa. Berdasarkan hal tersebut, item layanan yang menjadi prioritas pertama adalah Fakultas Teknik harus mengupayakan layanan yang sesuai dengan biaya kuliah yang dibayarkan (NP1). Prioritas kedua adalah perbaikan terhadap fasilitas ruang kelas (TB1). Prioritas ketiga terkait dengan metode pembayaran kuliah (NP2), prioritas keempat terkait dengan akses informasi yang berkaitan dengan akademik (E1), prioritas kelima terkait dengan akses jalan menuju kampus (TU3), prioritas keenam terkait dengan layanan dosen dan staf tata usaha saat membantu mahasiswa selama proses akademik (E3), prioritas ketujuh terkait dengan komunikasi antara dosen dan mahasiswa (RL2), dan prioritas kedelapan adalah ketersediaan buku dan jurnal yang sesuai dengan bidang mahasiswa pada perpusatakaan (TB2).

\section{DAFTAR PUSTAKA}

Aldridge, S., \& Rowley, J. (1998). Measuring customer satisfaction in higher education. Quality Assurance in Education, Vol. 6 , Number 4, 197204.

Alves, H., \& Raposo, M. (2007). Conceptual Model of Student Satisfaction in Higher Education. Total Quality Management and Business Excellence, Vol. 18, No. 5, 571-588.

Berger, C., Blauth, R., Boger, D., Bolster, C., Burchill, G., \& DuMouchel, W. (1993). A Special Issues on Kano's Methods for Understanding CustomerDefined Quality. Center for Quality Management Journal, Vol. 2, No. 4, 3-35.

Buchari, A. (2009). Manajemen Pemasaran dan Pemasaran Jasa, Cetakan kedelapan. Bandung: Alfabeta.

Cheruiyot, T. K., \& Maru, L. C. (2013). Service Quality and Relative Performance of Public Universities in East Africa. The TQM Journal, 533-546.

Debnath, R. M. (2011). Emerging Trend of Customer Satisfaction in Academic Process an Application SPC and Taguchi's Robust Parameter Design. TQM, 14-28.

Douglas, J., McClelland, R., \& Davies, J. (2007). The Development of a Conceptual Model of Student Satisfaction with Their Experience in Higher Education . Quality Assurance in Education, 1935.

Gabriel, L. E., Eric, S. M., \& Dorion, C. H. (2016). Service Quality Dimensions and Customer Satisfaction in Brazilian University Context. Benchmarking: An International Journal, Vol. 23 Iss 7, -.

Gruber, T., Fub, S., Voss, R., \& Glaser-Zikuda, M. (2010). Examining Student Satisfaction with Higher Education Services. International Journal of Public Sector Management Vol. 23 No. 2, 105123.

Ho, L. H., Feng, S. Y., \& Yen, T. M. (2013). A New Methodology for Customer Satisfaction Analysis: Taguchi's Signal-to-Noise Ratio Approach. Journal of Service Science and Management, 235244. 
Kumar, A., Motwani, J., \& Otero, L. (1996). An Application og Taguchi's Robust Experimental Design Technique to Improve Service Performance. International Journal of Quality and Reliability Management, 85-98.

Mendiknas. (2008). Peraturan Menteri Pendidikan Nasional No. 53 Tahun 2008 Pedoman Penyusunan SPM bagi PTN yang Menerapkan Pengelolaan Keuangan Badan Layanan Umum . Jakarta: Peraturan Menteri Pendidikan Nasional.

Raajpot, N., Javed, R., \& Koh, K. (2008). Application of Taguchi Design to Retail Service . International Journal of Commerce and Management, Vol. 18, No. 2, 184-199.

Shahin, A., \& Nasibeh, J. (2015). Developing The Kano Model by Service Quality Robust Design: an Integrative Approach. Journal of Productivity and Qualiy Management, Vol. 16, No.4, 373-389.
Soejanto, I. (2009). Desain Eksperimen dengan Metode Taguchi. Yogyakarta: Graha Ilmu.

Sukamto, I. (2016, Januari 6). Menristek Resmikan 36 Perguruan Tinggi Negeri Baru . Tempo, hal. -

Szymczak, M., \& Kowal, K. (2016). The Kano Model: Identification of Handbook Attributes to Learn in Practice. Journal of Workplace Learning, Vol. 28 Iss 5, 280-293.

Tan, K., \& Shen, X. (2000). Integrating Kano's Model in the Planning Matrix of Quality Function Deployment. Total Quality Management, Vol.11, No.8, 1114-1151.

Tjiptono, F., \& Chandra, G. (2004). Service, Quality, and Satisfaction. Yogyakarta: Andi.

WorldBank. (2011, Oktober 13). Pendidikan tinggi dapat memberikan kontribusi yang lebih besar bagi pembangunan Indonesia. The World Bank, hal. -. 